\title{
Enraizamento de estacas caulinares de Passiflora actinia Hook: concentrações de IBA e formas de aplicação
}

\author{
Rooting of Passiflora actinia Hook stem cuttings: IBA concentrations and application forms
Maíra Maciel Tomazzoli*, Cintia de Moraes Fagundes, Juliana de Oliveira Amatussi, Bruna Santos Klein Breiter e Katia Christina Zuffellato-Ribas

Universidade Federal do Paraná, Curitiba, PR, Brasil. *Autor para correspondência: mairatomazzoli@gmail.com.

Submissão: 26/03/2018 / Aceite: 25/02/2019

\begin{abstract}
RESUMO
O maracujá-do-mato (Passiflora actinia Hook) é utilizado como porta-enxerto para diferentes espécies de maracujá devido à sua tolerância à baixas temperaturas. Objetivou-se neste trabalho avaliar a eficiência da técnica de estaquia caulinar na propagação vegetativa de $P$. actinia em função de concentrações de ácido indol butírico (IBA) e método de aplicação. O experimento foi conduzido em casa de vegetação da Universidade Federal do Paraná, no período de agosto a outubro de 2016. Estacas semilenhosas com 10 $\mathrm{cm}$ de comprimento foram tratadas com 0, 1.500 e $3.000 \mathrm{mg} \mathrm{Kg}^{-1} / \mathrm{mg} \mathrm{L}^{-1}$ de IBA na forma de talco e em solução, plantadas em tubetes, o substrato foi vermiculita. Após 60 dias, foram avaliadas a porcentagem de enraizamento, presença de calos, sobrevivência, brotações novas, número de raízes/estacas e comprimento médio da maior raiz. A maior porcentagem de enraizamento $(85,94 \%)$ e número de raízes/estaca foram encontradas nos tratamentos com IBA na forma de talco, nas concentrações de 3.000 $\mathrm{mg} \mathrm{kg}^{-1}$ e $1.500 \mathrm{mg} \mathrm{Kg}^{-1}$, respectivamente. A estaquia de $P$. actinia é um método de propagação eficiente. $\mathrm{O}$ uso de IBA, em ambas as formas de aplicação, promoveu de forma eficiente o enraizamento da espécie, sendo recomendada a aplicação na concentração de $1.500 \mathrm{mg} \mathrm{Kg}^{-1}$ ou mg L-1.
\end{abstract}

PALAVRAS-CHAVE: estaquia, maracujá-do-mato, ácido indol butírico, solução, talco.

\begin{abstract}
The Caatinga passion fruit (Passiflora actinia Hook) is used as rootstock for different passion fruit species due to its tolerance to low temperatures. This study aimed to evaluate the efficiency of the stem cutting technique in the vegetative propagation of $\mathrm{P}$. actinia according to different concentrations of indole butyric acid (IBA) and application methods. The experiment was conducted in the greenhouse of Federal University of Parana, between August and October 2016. Semi-woody stem cuttings measuring $10 \mathrm{~cm}$ long were treated with 0,1500 , and $3000 \mathrm{mg} \mathrm{Kg}^{-1} / \mathrm{mg} \mathrm{L}^{-1}$ IBA in talc and solution, and then planted in plastic tubes with vermiculite as substrate. After 60 days, the stem cuttings were evaluated for rooting percentage, presence of callus, survival, new shoots, number of roots per cuttings and average length of the longest root. The best rooting percentage (85.94\%) and number of roots/cuttings were found in cuttings treated with IBA in talc at $3.000 \mathrm{mg} \mathrm{Kg}^{-1}$ and $1.500 \mathrm{mg} \mathrm{Kg}^{-1}$, respectively. P. actinia propagation by stem cuttings is an efficient method. IBA, in both application forms, efficiently promoted the rooting of the species and can be recommended at the concentration of $1.500 \mathrm{mg} \mathrm{Kg}^{-1}$ or mg L-1.
\end{abstract}

KEYWORDS: cutting, caatinga passion fruit, IBA, solution, talc.

O gênero Passiflora possui cerca de 400 espécies, as quais são nativas de diversas regiões. Estre essas espécies, as mais cultivadas para obtenção de frutos comerciais refere-se ao maracujá (Passiflora edulis Sims e $P$. edulis f. flavicarpa Degener). O maracujá é conhecido por suas características nutricionais e organolépticas, sendo amplamente produzido e consumido no mundo. A espécie Passiflora actinia Hook, popularmente conhecida como maracujá-do-mato, possui metabólitos secundários de interesse medicinal além de ser apreciada para alimentação humana (JUNIOR et al. 2013). Tradicionalmente, é utilizada para o tratamento de ansiedade, insônia e outros distúrbios causados por problemas nas concentrações de glutamato e seus receptores. Análises verificaram grande eficiência na ação sedativa, e identificaram como principais constituintes bioativos os flavonoides C-glicosil (SANTOS et al. 2016). Além disso, também é 
muito utilizada como porta-enxerto para diversas outras espécies de maracujá, devido sua tolerância às baixas temperaturas (JUNIOR et al. 2013).

A propagação de espécies do gênero Passiflora pode ser realizada por sementes, enxertia e estaquia. Uma das dificuldades da propagação sexuada nessa cultura são os pomares com alta variabilidade, além do tempo de dormência das sementes (MELETTI et al. 2002). Em contrapartida, a propagação de maracujazeiro por meio da estaquia propicia a obtenção de plantas homogêneas e a multiplicação de plantas produtivas (LIMA et al. 2007), formando pomares de qualidade (RONCATTO et al. 2008) e tecnicamente superiores (SANTOS et al. 2012).

Na propagação vegetativa, o enraizamento pode ser influenciado por diversos fatores, entre eles a área foliar deixada na confecção das estacas. As folhas devem ter tamanho adequado para a produção e translocação de fotoassimilados sem causar a perda de água por transpiração (SANTOS et al. 2012). Quando se realiza o corte das folhas pela metade, o excesso de perda de água por transpiração é evitado, aumentando a viabilidade da estaca e consequentemente a chance de sucesso no enraizamento (MELETTI et al. 2002).

Há uma carência de informações técnicas a respeito da propagação por estaquia em escala comercial no cultivo de maracujá-do-mato (ARAUJO et al. 2004, SANTOS et al. 2012). A falta de uniformidade no enraizamento de P. actinia (MELETTI et al. 2002), instiga a necessidade de estudos que definam as melhores concentrações de reguladores vegetais e o melhor tipo de veiculação para a espécie em questão. $O$ uso de reguladores vegetais contribui para o enraizamento e formação de raízes de qualidade, mas a sua aplicação pode apresentar diferentes respostas dependendo do material vegetal utilizado (ARAUJO et al. 2010). Sendo assim, foi desenvolvido um experimento com o objetivo de avaliar a eficiência da técnica de estaquia na propagação vegetativa de Passiflora actinia Hook em função de diferentes concentrações de IBA e formas de aplicação.

O experimento foi conduzido em casa de vegetação do Setor de Ciências Biológicas da Universidade Federal do Paraná, em Curitiba, PR, localizada a $25^{\circ} 25^{\prime} 40^{\prime \prime} \mathrm{S}$ e $49^{\circ} 11^{\prime} 23^{\prime \prime} \mathrm{O}$ e altitude média de $934 \mathrm{~m}$, durante o período de agosto de 2016 a outubro de 2016. Segundo a classificação de Köppen, o clima da região é do tipo Cfb (clima temperado).

Estacas caulinares de Passiflora actinia Hook obtidos a partir de indivíduos adultos, localizados no Jardim Botânico de Curitiba, PR, foram coletados em agosto de 2016. A partir da porção mediana destes, foram confeccionadas estacas semilenhosas com $10 \mathrm{~cm}$ de comprimento e diâmetro médio de 3,2 mm. Para o preparo das estacas procedeu-se o corte reto no ápice e em bisel na base, deixando uma folha na porção apical com sua área reduzida à metade. Durante este processo, as estacas foram mantidas em um recipiente contendo água, a fim de evitar sua desidratação. Posteriormente, realizou-se 0 tratamento fitossanitário das mesmas, por imersão, durante 10 minutos em hipoclorito de sódio 0,5\%, sendo as estacas posteriormente lavadas em água corrente por mais 10 minutos.

As estacas foram então submetidas aos tratamentos com IBA nas concentrações de $1.500 \mathrm{mg} \mathrm{L}^{-1} \mathrm{e}$ $3.000 \mathrm{mg} \mathrm{L}^{-1}$ ou mg Kg${ }^{-1}$, veiculados em solução hidroalcóolica $50 \%$, v/v, por 10 segundos de imersão e em talco, além da testemunha (somente água). Posteriormente, realizou-se o plantio das estacas em tubetes de polipropileno com capacidade para $53 \mathrm{~cm}^{3}$, contendo vermiculita de granulometria fina como substrato, sendo mantidas em casa de vegetação climatizada, programada para $25 \stackrel{\circ}{\circ} \mathrm{C} 2{ }^{\circ} \mathrm{C}$ e $95 \%$ de umidade relativa. O delineamento experimental utilizado foi o inteiramente casualizado, com quatro repetições de 16 estacas por unidade experimental, totalizando 64 estacas por tratamento.

Após 60 dias foi realizada a avaliação do experimento, sendo analisadas as seguintes características: estacas enraizadas (estacas com raízes de, no mínimo, $1 \mathrm{~mm}$ de comprimento); número de raízes/estaca (total de raízes emitidas); comprimento de raízes/estaca (comprimento das três maiores raízes formadas por estaca, em cm); estacas com calos (estacas vivas com formação de massa celular indiferenciada na base e sem raízes); estacas vivas (estacas vivas que não apresentavam indução radicial nem formação de calos); e estacas brotadas (estacas que apresentaram emissão de novas brotações).

Os dados foram avaliados quanto a homogeneidade das variâncias dos tratamentos pelo teste de Bartlett. Em seguida, foi aplicado o teste $F$ de análise de variância (ANOVA) e quando significativo, os dados foram submetidos ao teste de separação de médias de Tukey $(p<0,05)$.

O teste de comparação de médias revelou que, para os resultados de porcentagem de enraizamento, houve diferença entre os tratamentos utilizados (Tabela 1). Verificou-se que a concentração de 3.000 $\mathrm{mg} \mathrm{Kg}^{-1}$ de IBA proporcionou a maior média de enraizamento (85,94\%), diferindo-se da testemunha e de $3.000 \mathrm{mg} \mathrm{L}^{-1}$ IBA. A capacidade de enraizamento das estacas pode ser influenciada tanto por fatores endógenos como exógenos da planta como, por exemplo, o tipo de substrato, fatores ambientais, uso de 
reguladores de crescimento exógeno, condições fisiológicas da planta matriz, idade da planta matriz, época de estaquia, tipo de estaca (herbácea, semi-lenhosa e lenhosa), ação de agentes oxidantes endógenos da planta, presença de carboidratos, substâncias nitrogenadas, aminoácidos, auxinas, compostos fenólicos, dentre outros. Quando essas substâncias se encontram presentes em concentrações e proporções adequadas, acumulam-se em regiões de regeneração das raízes, contribuindo para a emissão de raízes adventícias (CHALFUN \& HOFFMAN 1997, HARTMANN et al. 2002).

Tabela 1. Porcentagem de enraizamento, número de raízes/estaca e comprimento das raízes/estaca de Passiflora actinia, em função de diferentes concentrações de IBA (1.500 e $3.000 \mathrm{mg} \mathrm{Kg}^{-1}$; $\left.\mathrm{mg} \mathrm{L}^{-1}\right)$ e testemunha.

Table 1. Rooting percentage, root/stem number and root/stem length of Passiflora actinia cutting, as a function of different concentrations of IBA (1,500 and 3,000 mg Kg-1; mg L-1) and control.

\begin{tabular}{cccc}
\hline Tratamentos & Enraizamento $(\%)$ & $\mathrm{N}^{\circ}$ de raízes/estaca & $\begin{array}{c}\text { Comprimento de } \\
\text { raízes/estaca }(\mathrm{cm})\end{array}$ \\
\hline Testemunha & $67,19 \mathrm{bc}^{*}$ & $3,89 \mathrm{~b}$ & $4,89 \mathrm{a}$ \\
$1.500\left(\mathrm{mg} \mathrm{L}^{-1}\right)$ & $79,69 \mathrm{ab}$ & $7,41 \mathrm{ab}$ & $6,12 \mathrm{a}$ \\
$3.000\left(\mathrm{mg} \mathrm{L}^{-1}\right)$ & $62,50 \mathrm{c}$ & $7,29 \mathrm{ab}$ & $6,31 \mathrm{a}$ \\
$1.500\left(\mathrm{mg} \mathrm{Kg}^{-1}\right)$ & $79,69 \mathrm{ab}$ & $11,04 \mathrm{a}$ & $6,49 \mathrm{a}$ \\
$3.000\left(\mathrm{mg} \mathrm{Kg}^{-1}\right)$ & $85,94 \mathrm{a}$ & $6,64 \mathrm{ab}$ & $5,75 \mathrm{a}$ \\
\hline $\mathrm{CV}^{1}$ & 10,32 & 37,37 & 22,95 \\
\hline
\end{tabular}

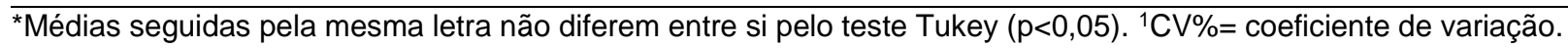

Para muitas espécies vegetais a aplicação exógena de auxina é decisiva para aumentar a capacidade de enraizamento da planta (VILLA et al. 2003). Entretanto, estudos realizados por KOCH et al. (2001) verificaram que a espécie $P$. actinia pode ser propagada sem a necessidade de utilização do regulador vegetal, fato este que difere do ocorrido no presente trabalho, onde a porcentagem de enraizamento das estacas aumentou de 12,5 - 18,75\% com a aplicação exógena de ácido indol butírico, para quase todos os tratamentos testados. Este incremento na capacidade de enraizamento pode ter ocorrido devido à baixa concentração de auxina endógena das estacas, sendo necessária a suplementação do regulador vegetal para alcançar a máxima capacidade de emissão de raízes.

A forma de veiculação do regulador vegetal, líquida ou sólida, também afetou a porcentagem de enraizamento das estacas quando aplicada a concentração de $3.000 \mathrm{mg} \mathrm{Kg}^{-1}$ ou mg L $\mathrm{L}^{-1}$ de IBA (Tabela 1). A veiculação sólida apresentou maior efeito no enraizamento quando comparado a veiculação líquida, podendo isto ser atribuído a melhor aderência do regulador na base da estaca, ocasionando maior eficiência na indução de raízes (ALEXANDRE et al. 2014). Estudos de YAMAMOTO et al. (2010) em avaliação do enraizamento de estacas de Psidium guajava L. tratadas com diferentes concentrações de IBA e formas de veiculação, constataram que estacas que receberam o regulador em talco apresentaram as maiores porcentagens de enraizamento, corroborando com o que foi observado neste estudo para a espécie $P$. actinia.

Para o número de raízes por estaca, a forma de aplicação e a concentração do regulador vegetal apresentaram diferenças estatísticas entre os tratamentos testados (Tabela 1). O menor número de raízes/estaca foi observado em estacas que não receberam o tratamento com o regulador vegetal (testemunha). Embora a forma de aplicação em talco não tenha diferido da aplicação em solução, o maior número de raízes ocorreu quando se aplicou a concentração de $1.500 \mathrm{mg} \mathrm{Kg}^{-1}$ de IBA. A aplicação de IBA $3.000 \mathrm{mg} \mathrm{Kg}^{-1}$ acarretou na redução do número de raízes/estaca, evidenciando que o uso de IBA, em concentrações mais elevadas, é capaz de ocasionar toxicidade nas mesmas.

SABIÃO et al. (2011), obtiveram respostas diferentes às do presente estudo, onde o maior número de raízes/estaca em Passiflora nitida foi observado em concentrações mais altas de IBA, de 3.000 a 5.000 $\mathrm{mg} \mathrm{L}^{-1}$. Os mesmos concluíram que o uso do regulador vegetal pode ter influenciado na melhor formação de raízes, por meio da divisão celular que ocorre nas estacas.

As características comprimento de raízes/estaca (Tabela 1), estacas com calos, estacas mortas e brotações novas (Tabela 2), não apresentaram diferenças estatísticas significativas entre os tratamentos testados.

Como exposto anteriormente, foram consideradas estacas vivas (Tabela 2) aquelas que não apresentaram raízes nem calos. Para esta variável, a análise de variância apresentou diferenças significativas entre os tratamentos. De forma contrária ao que foi apresentado nos resultados de 
porcentagem de enraizamento, a aplicação de IBA $3.000 \mathrm{mg} \mathrm{Kg}^{-1}$ apresentou a menor porcentagem de estacas vivas, diferindo do melhor resultado (IBA $3.000 \mathrm{mg} \mathrm{L}^{-1}$ ).

Tabela 2. Porcentagem de estacas com calos, estacas vivas, estacas mortas e brotações novas de Passiflora actinia, em função de diferentes concentrações de IBA $\left(1.500\right.$ e $\left.3.000 \mathrm{mg} \mathrm{Kg}^{-1} ; \mathrm{mg} \mathrm{L}^{-1}\right) \mathrm{e}$ testemunha.

Table 2. Percentage of cuttings with callus, live cuttings, dead cuttings and new shoots of Passiflora actinia, according to different concentrations of IBA (1,500 and 3,000 mg Kg-1; mg L-1) and control.

\begin{tabular}{ccccc}
\hline Tratamentos & $\begin{array}{c}\text { Estacas com } \\
\text { calos }(\%)\end{array}$ & $\begin{array}{c}\text { Estacas vivas } \\
(\%)\end{array}$ & $\begin{array}{c}\text { Estacas mortas } \\
(\%)\end{array}$ & $\begin{array}{c}\text { Brotações novas } \\
(\%)\end{array}$ \\
\hline Testemunha & $6,25 \mathrm{a}^{*}$ & $14,06 \mathrm{ab}$ & $12,5 \mathrm{a}$ & $32,81 \mathrm{a}$ \\
$1.500\left(\mathrm{mg} \mathrm{L}^{-1}\right)$ & $1,56 \mathrm{a}$ & $6,25 \mathrm{ab}$ & $12,5 \mathrm{a}$ & $34,38 \mathrm{a}$ \\
$3.000\left(\mathrm{mg} \mathrm{L}^{-1}\right)$ & $1,56 \mathrm{a}$ & $17,19 \mathrm{a}$ & $18,75 \mathrm{a}$ & $25,00 \mathrm{a}$ \\
$1.500\left(\mathrm{mg} \mathrm{Kg}^{-1}\right)$ & $0,00 \mathrm{a}$ & $10,94 \mathrm{ab}$ & $9,38 \mathrm{a}$ & $17,19 \mathrm{a}$ \\
$3.000\left(\mathrm{mg} \mathrm{Kg}^{-1}\right)$ & $3,13 \mathrm{a}$ & $3,13 \mathrm{~b}$ & $4,69 \mathrm{a}$ & $26,56 \mathrm{a}$ \\
\hline $\mathrm{CV}^{1}$ & $136,93 \%$ & $56,96 \%$ & $73,52 \%$ & $57,93 \%$ \\
\hline
\end{tabular}

${ }^{*}$ Médias seguidas pela mesma letra não diferem entre si pelo teste Tukey $(p<0,05) .{ }^{1} \mathrm{CV} \%=$ coeficiente de variação.

A estaquia de Passiflora actinia Hook é um método de propagação eficiente. O uso de IBA em ambas as formas de aplicação, promoveu de forma eficiente o enraizamento da espécie, sendo recomendada a sua aplicação na concentração de $1.500 \mathrm{mg} \mathrm{Kg}^{-1}$ ou mg L-1.

\section{AGRADECIMENTOS}

Aos colegas do Grupo de Estudo e Pesquisa em Estaquia (GEPE) pelo auxílio durante a execução do experimento e também ao Departamento de Botânica da Universidade Federal do Paraná pela disponibilidade de equipamentos e estrutura física.

\section{REFERÊNCIAS}

ALEXANDRE RS et al. 2014. Enraizamento adventício de estacas do maracujazeiro silvestre Passiflora mucronata Lam.: forma de veiculação e concentrações do ácido indol-3-butírico. Revista Ceres 61: 567-571.

ARAUJO FP et al. 2010. Substratos e concentrações de ácido indolibutírico no enraizamento de estacas de Passiflora cincinnata Mast. Magistra 22: 21-27.

ARAUJO FP et al. 2004. Propagação vegetativa do maracujá-do-mato: espécie resistente à seca, de potencial econômico para agricultura de sequeiro. Petrolina: Embrapa Semiárido. 2p. (Instruções Técnicas).

CHALFUN NNJ \& HOFFMANN A. 1997. A propagação do pessegueiro e da ameixeira. Informe Agropecuário 18: 23-29.

HARTMANN HT et al. 2002. Plant propagation: principles e practices. 1.ed. New Jersey: Prentice Hall. 880p.

JUNIOR CLA et al. 2013. Enraizamento de estacas semilenhosas de maracujazeiro amarelo Passiflora actinia Hook. Semina: Ciências Agrárias 34: 3663-3668.

$\mathrm{KOCH}$ RC et al. 2001. Vegetative propagation of Passiflora actinia by semihardwood cuttings. Semina: Ciências Agrárias 22: $165-167$.

LIMA DM et al. 2007. Influência de estípulas foliáceas e do número de folhas no enraizamento de estacas semilenhosas de maracujazeiro amarelo nativo. Acta Scientiarum. Agronomy 29: 671-676.

MELETTI LMM et al. 2002. Novas tecnologias melhoram a produção de mudas de maracujá. O Agronômico 54: 30-33.

RONCATTO G et al. 2008. Enraizamento de estacas de espécies de maracujazeiro (Passiflora spp.) no inverno e no verão. Revista Brasileira de Fruticultura 30: 1089-1093.

SABIÃO RR et al. 2011. Enraizamento de estacas de Passiflora nitida submetidas a diferentes concentrações de ácido indolbutírico (AIB). Revista Brasileira de Fruticultura 33: 654-657.

SANTOS KC et al. 2016. Passiflora actinia hydroalcoholic extract and its major constituent, isovitexin, are neuroprotective against glutamate-induced cell damage in mice hippocampal slices. Journal of Pharmacy and Pharmacology 68: 282-291.

SANTOS JL et al. 2012. Propagação vegetativa de estacas de Passiflora cincinnata Mast. em diferentes recipientes e substratos comerciais. Revista Brasileira de Fruticultura 34: 581-588.

VILLA F et al. 2003. Propagação de amoreira preta utilizando estacas lenhosas. Ciência Agrotecnologia 27: 829-834.

YAMAMOTO LY et al. 2010. Enraizamento de estacas de Psidium guajava L. 'Século XXI' tratadas com ácido indolbutírico veiculadas em talco e álcool. Ciência Rural 40: 1037-1042. 